\title{
Apophysomyces variabilis a flesh eating fungus - a case report
}

\author{
Dr. Vijay Kumar Gowdara shankarappa ${ }^{1,}$ Dr. Sowmya G Shivappa ${ }^{2,}$ Dr. Madhu \\ Chandgal Puttaswamy ${ }^{3}$, Miss. Rashmi Ramakrishna ${ }^{4}$, \\ Dr. Ramya Ramalingaiah ${ }^{5}$, Dr.Varsha Puranik ${ }^{6}$ \\ ${ }^{I}$ Professor and Head, department of Microbiology, JSS Medical College, JSS University, Mysore, India 570015) \\ ${ }^{2}$ Assistant Professor, Department of Microbiology, JSS Medical College, JSS University, Mysore 570015) \\ ${ }^{3}$ Professor of Surgery, JSS Medical College and Hospital, JSS University, Mysore, INDIA 570015) \\ ${ }^{4}$ Research scholar, Department of Microbiology, Defence Food Research Laboratory, Mysore-11) \\ ${ }^{5}$, Research Scholar, Department of Microbiology, JSS Medical College, JSS University, Mysore- 570015) \\ ${ }^{6}$ Research Scholar, Department of Microbiology, JSS Medical College, JSS University, Mysore- 570015
}

\begin{abstract}
:
Background: Modern therapeutic methods, addictive habits and increased usage of immunosuppressive medications have escalated human susceptibility to opportunistic fungal infections. Genus Apophysomyces is an opportunistic fungus causing infections in immunocompetent individuals. Apophysomyces variabilis is one of the four species often causing fatal cutaneous infections.

Case report: An elderly male presented with a painful necrotizing lesion on the anterior abdominal wall over right iliac fossa. Twenty days prior he was admitted to hospital for Zoster on the same spot and was treated with acyclovir. He had persisting post herpetic neuralgia. The pain became very intense about 5 days back and an analgesic patch was applied by the local practitioner. An erythema was noticed about 4 days ago, which developed to the present necrotizing lesion involving the entire abdominal wall.

Methodology: White cottony growth arising from the lesion grew a rapidly growing fungus which was confirmed by phenotypic and genotypic characters as. A. Variabilis. Patient was treated with intravenous Amphotericin B and Voriconazole, but he succumbed. The isolate was deposited in the genebank (KF 147910) Conclusion: Newer rapidly fatal fungal infections need to be included in the differential diagnosis of all necrotizing lesions. Awareness of such lesion among microbiologist is vital. A.Variabilis is a thermotolerant soil fungi capable of causing acute fatal infections in humans . Contamination of medications, dressings and also any exposed wound may end fatally.
\end{abstract}

Key words; Apophysomyces, varaiabilis, thermotolerant

\section{Introduction}

Intravenous drug use, haematological malignancies, long term steroid therapy and other immunosuppressive conditions have resulted in defective phagocytosis, inefficient intracellular killing and increasing the risk of acquiring opportunistic mycosis, some of which are often rapidly fatal. Apophysomycosis, is a rare opportunistic mycotic disease seen in immunocompetent persons( 1) caused by one of the four species in the genus Apophysomyces. Apophysomyces species are worldwide in distribution. There are four species- A.elegans, A.variabilis ,A.trapezius and A.ossiformis which are thermotolerant, angio invasive soil inhabiting fungi. Apophysomyces infections are not very common ${ }^{2}$ but invasive surgeries, steroids, old age and excessive usage of antibiotics ${ }^{3}$ makes the person highly vulnerable to Apophysomycosis .Only three case reports are published in India till date. Slide culture microscopic finding of mixed morphological sporngiospore forms, makes this the first fatal case report due to Apophysomyces Variabilis.

\section{Case report:}

64 years male patient with an anterior abdominal wall necrotizing fasciitis was brought to the surgery clinic by his wife. She informed that he was admitted in the same hospital about 20 days earlier for Herpes Zoster in the right iliac region. He was treated with parenteral \& oral Acyclovir for ten days and was discharged. About four to five days after discharge from the hospital, patient developed intolerable post herpetic neuralgia. An analgesic patch was applied on to the site of zoster lesion by the local practitioner. During the next two to three days he noticed progressive redness leading to necrosis. That was when he was brought to hospital. Preliminary clinical diagnosis was "bullous fixed drug reaction". On examination coarse crepitations were heard over the lungs. Wife also informed about chronic breathing problem and was taking a very tiny tablet daily for several years. His earlier (old) medical records showed that he was a case of Bronchiectasis and was placed on cortisone $(5 \mathrm{mg})$. 
Preliminary laboratory results showed a total WBC count of 17,500 cells/ cu.mm, Blood urea 68 $\mathrm{mg} / \mathrm{dl}$, Serum creatinine $2.7 \mathrm{mg} / \mathrm{dl}$; haemoglobin level dropped from $11.9 \mathrm{~g} / \mathrm{dl}$ to $9 \mathrm{~g} / \mathrm{dl}$, and random blood sugar $300 \mathrm{mg} / \mathrm{dl}$, although he was not a known diabetic. He was treated conservatively with antibiotics and analgesics. Next day the lesion had increased in size and the diagnosis was changed to 'necrotizing fasciitis'. An extensive debridement was immediately done. Twenty four hours later white cottony growth along the marginof the necrosed tissue was noticed. Emergency second debridement was done and the cottony growth was sent for fungus culture It was Cultured on Sabourauds dextrose agar (SDA) and incubated at 25 degree Celsius. Following the second debridement he was also treated with intravenous Amphotericin B 70mg/day and voriconazole $200 \mathrm{mg} /$ day. Subsequently he developed respiratory distress and was given ventilator support. But his condition deteriorated and he succumbed on the $5^{\text {th }}$ day of hospitalization.

\section{Mycological Laboratory findings:}

Potassium hydroxide preparation of the white growth showed sterile broad aseptate hyphae. Culture on Sabouraud's dextrose agar (SDA) yielded yellowish white tube filling powdery fungal growth within $48 \mathrm{~h}$. Microscopic examination of lactophenol tease mount preparation showed broad aseptate sterile hyphae,. Slide culture was put up and incubated at both $25^{\circ} \mathrm{C}$ and $40^{\circ} \mathrm{C}$. Unbranched sporangiophores with prominent funnelshaped apophyses (Fig 2) and pyriform sporangia along with few rectangular spores were observed in the slide culture after ten days. Variation in the size and shape of the sporangiospore and darkened area below the apophysis was also noticed. The culture was thermo-tolerant up to $40^{\circ} \mathrm{C}$. Based on these phenotypic characters, we made a provisional identification of Apophysomyces variabilis (Fig. 2), which is referred to in this manuscript as JSS AP. Further confirmation was done by DNA extraction, gene sequencing of internal transcriber spiformisacer (ITS) regions and comparing the sequence with twenty eight sequences of Apophysomyces spp. deposits from Genbank.

\section{Genesequencing \& Phylogenetic analysis}

Genomic DNA from JSS AP isolate was prepared from mycelia grown in potato dextrose broth at $30^{\circ} \mathrm{C}$ for $72 \mathrm{hrs}^{6}{ }^{6}$ PCR assays were performed using the ITS1 and ITS4 primers. ${ }^{7}$ The amplicon was purified with the Genelute PCR purification kit (Sigma, Bangalore, India) and cloned into pTZ57R/T TA cloning vector. The recombinant vector was transformed into E. coli DH5 $\alpha$ (Invitrogen, Bangalore, India) and clones were screened by PCR. Plasmids were extracted from three individual PCR positive clones using Genelute Plasmid extraction kit (Sigma, Bangalore, India) and the insert sequenced from Eurofins, Bangalore, India. The sequences were assembled using Gene Runner software ${ }^{8}$ and the resulting ITS1-ITS4 sequence was used to perform BLASTn searches. ${ }^{9}$. The search returned a total of 28 Apophysomyces sequences at average significant identities of $\geq 80 \%$. All the FASTA sequences were retrieved from the blast hits to analyze the phylogenetic position of JSS AP isolate. Our sequence data was compared with those obtained in thirteen A. variabilis, eight A. elegans, five A. trapeziformis and two A. ossiformis to evaluate the effect of genetic admixture. The neighbour joining based phylogenetic analyses were performed using p-distance parameters in MEGA $5^{10}$ and 1000 generations were run for bootstrap analysis. The results showed a pronounced divergence among these species. Phylogenetic analysis using ITS1-5.8S rRNA-ITS2 sequencing showed JSS AP isolate to be more closely related to A. variabilis than to the other three species, viz., A. ossiformis, A. trapeziformis and A. elegans. It can be observed from Figure 3 that the four major clades of identical or nearly identical sequences (Cluster 1 through 4) appeared as observed by Alvarez et al., 2010. ${ }^{5}$ In general, smaller genetic distances observed between A. ossiformis and A. trapeziformis pair (0.002-0.01) and A. elegans and A. variabilis pair (0.01-0.012) as observed in previous studies $^{5}$ (Table 1). The JSS AP isolate was found to be morphologically and phylogentically closer to A. variabilis, and due to high bootstrap value (80) of the novel clade, we are of the opinion that the isolate may be a new subspecies A. variabilis subsp. Variabilis.(22)

\section{Discussion:}

Apophysomyces variabilis is an angioinvasive fungus causing rapidly progressing necrotizing vasculitis. ${ }^{11}$ Apophysomyces species are known immunosuppressants, which suppress the pathogen recognition genes and evade human defence resulting in fasciitis. ${ }^{12 .}$ The incidence of A. variabilis in humans is unknown and difficult to ascertain due to lack of awareness and no data in the diagnostic laboratories. . Epidemiology of Apophysomyces infections is poorly understood and globally these infections are underreported solely due to delayed sporulation on routine media. ${ }^{16}$

5.1. Case reviews and Clinical types of Apophysomyces: Apophysomycosis was first detected in 1979,. Apophysomycosis can manifest as spontaneously healing cutaneous lesion or as a rapidly disseminating fatal infection involving renal or central nervous system18.inhalation may lead to fatal pulmonary and rhinocerebral type. It can be transmitted nosocomally through contaminated Medications and dressing materials. In the present case exact source for apophysomycosis could not be detected. Spores may have been from the environment, 
scratching / rubbing of the area might have led to multiplication and necrosis, insect bites, burn wounds, topical lotions and hyperglycaemic status also favour transmission of apophysomyces. 20 . associated favourable conditions are diabetic ketoacidosis, increased iron uptake and natural disasters such as tsunami and tornado ${ }^{27}$

Even after molecular and ecological analysis, many questions regarding Apophysomyces such as epidemiology, pathophysiology, frequency of exposure to environmental source, geographical location and the infective dose remain unanswered. The present case study reported here is only the third case of apophysomycosis and the first case of A.variabilis infection in South India. This is the first case of fatal anterior abdominal wall necrotising fasciitis due to A. variabilis following application of an analgesic patch. ${ }^{31}$

\section{Summary:}

In conclusion it can be said that suspicion of a possible fungal etiology in all cases of fasciitis must be looked for and early diagnosis and proper antifungal therapy will save such patients

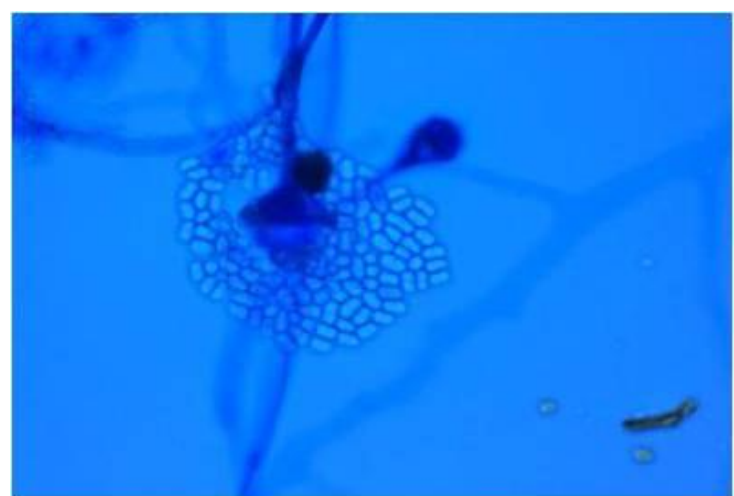

Fig 1 showing varying Sporangiospores

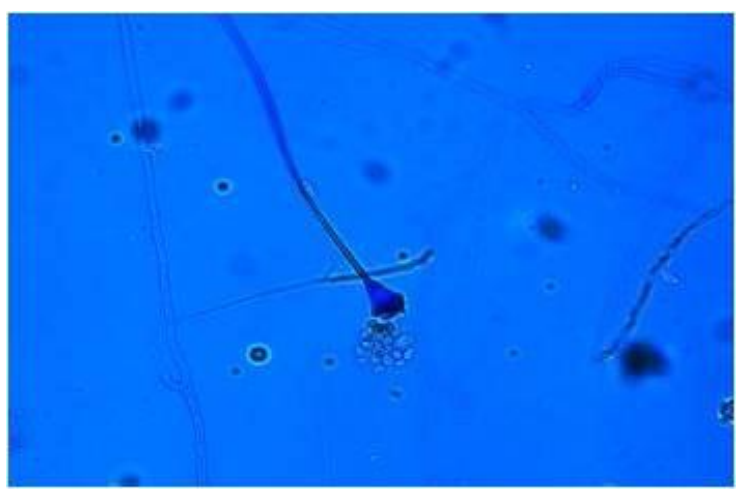

Fig 2 showing funnel shaped Apophyces 


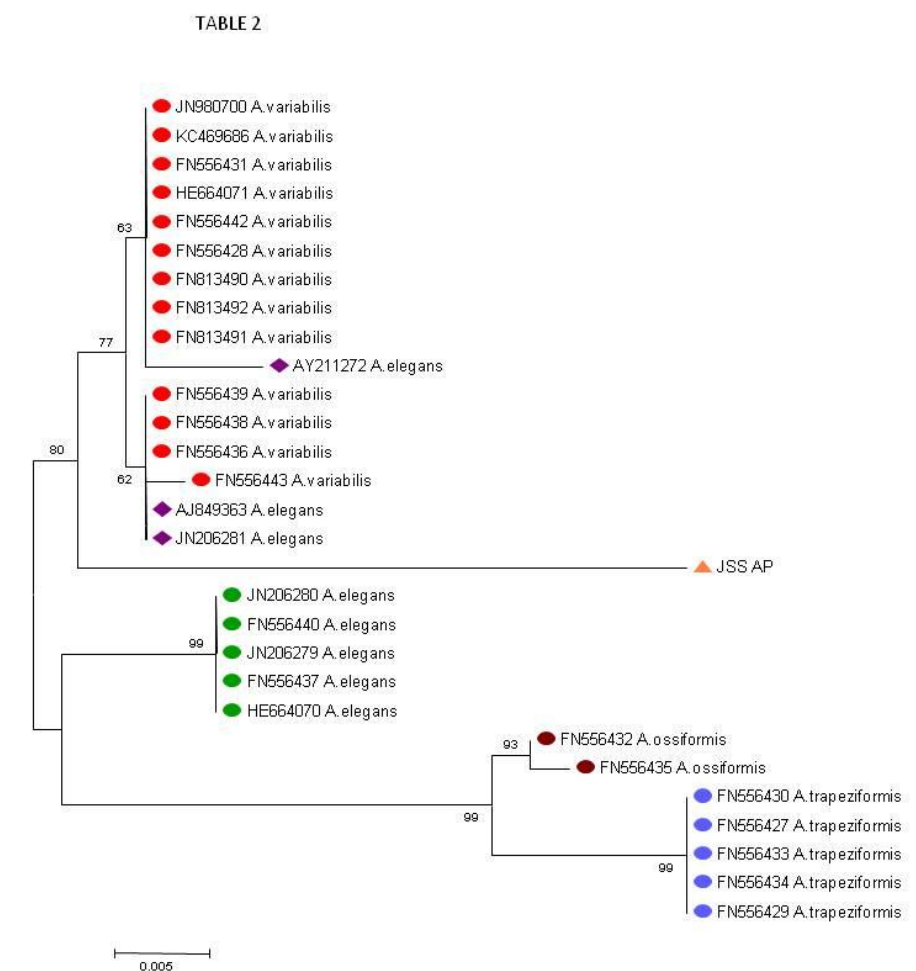

Table 2 :N eighbor -Joining dendrogram of the genetic distances (DA) among

various

Apophysomyces species and JSS AP isolate.

\section{Conflict}

All the authors have read the manuscript and have no conflict of interest. No funding has been received from any organisation

We thank the patient for cooperation

\section{Acknowledgement}

\section{References}

[1] Rippon JW. Zygomycosis. In: Wonsiewicz M, 1998 ed. Medical Mycology. The Pathogenic Fungi and the Pathogenic Actinomycetes. $3^{\text {rd }}$ ed. Philadelphia, Pa: W.B. Saunders; :681-713

[2] Rinaldi MG. Zygomycosis1989. Infect Dis Clin North Am :19-41.

[3] John R. Perfect and Wiley A. Schell;1996. The New Fungal Opportunists Are Coming. CID ;22 (Suppl 2)

[4] Misra PC, Srivastava KJ, Lata K.1979 Apophysomyces, a new genus of Mucorales. Mycotaxon ;8:377-82

[5] Alvarez E, Stchigel AM, Cano J, Sutton DA, Fothergill AW, Chander J, Salas V, Rinaldi MG, Guarro J; 2010; Molecular phylogenetic diversity of the emerging mucoralean fungus Apophysomyces: proposal of three new species. Rev Iberoam Micol. 2010; 27:80-9. DOI: 10.1016/j.riam.2010.01.006

[6] Rashmi, R., Ramana, M.V., Shylaja, R., Uppalapati, S.R., Murali, H.S. and Batra, H.V. (2013), Evaluation of a multiplex PCR assay for concurrent detection of four major mycotoxigenic fungi from foods. Journal of Applied Microbiology, 114: 819-827.

[7] 7. White TJ, Bruns T, Lee S and Taylor J (1990) Amplification and direct sequencing of fungal ribosomal RNA genes for phylogenetics. In: Innis MA, Gelfand DH, Sninsky JJ and White TJ (eds) PCR protocols. A guide to methods and applications. Academic Press,(1990) San Diego, pp. 315-322.

[8] (http://www.generunner.net/)

[9] http://www.ncbi.nlm.nih./BLAST/.

[10] Tamura K, Peterson D, Peterson N, Stecher G, Nei M, and Kumar S (2011) MEGA5: Molecular Evolutionary Genetics Analysis using Maximum Likelihood, Evolutionary Distance, and Maximum Parsimony Methods. Molecular Biology and Evolution; 2011;28: 2731-2739.

[11] Kimura, M., M. B. Smith, and M. R. McGinnis. 1999. Zygomycosis due to Apophysomyces elegans: report of 2 cases and review of the literature. Arch. Pathol. Lab. Med. 1999; 123:386-390. Medline

[12] Ashraf S. Ibrahim, Host Cell Invasion in Mucormycosis:2011 Role of Iron; Curr Opin Microbiol. August; 14(4): 406 
[13] 13.Chakrabarti A, Chatterjee SS, Shivaprakash MR..2008; Overview of opportunistic fungal infections in India. Nippon Ishinkin Gakkai Zasshi. ; 49:165-172

[14] 14. Chakrabarti A, Chatterjee SS, Das A, Panda N, Shivaprakash MR, Kaur A, Varma SC, Singhi S, Bhansali A, Sakhuja V. 2009; Invasive zygomycosis in India: experience in a tertiary care hospital. Postgrad Med J. ; 85:573-581. [PubMed: 19892892] cross references

[15] 15. Chakrabarti A, Ghosh A, Prasad GS, David JK, Gupta S, Das A, 2003;Apophysomyces elegans: an emerging zygomycete in India. J Clin Microbiol. ; 41:783-8.

[16] 16. Padhye AA, Ajello L. 1988;Simple method of inducing sporulation by Apophysomyces elegansand Saksenaea vasiformis. J Clin Microbiol. ; 26:1861-3.

[17] 17. Ana M. Cáceres, Carlos Sardiñas, Carmen Marcano, Rafael Guevara, Jorge Barros, Gino Bianchi, Vicente Rosario, Ronald Balza,Marisela Silva, Maria C. Redondo, María Nuñez, Aug 1997; Apophysomyces elegans Limb Infection with a Favorable Outcome: Case Report and Review Clinical Infectious Diseases, Vol. 25, No. 2, pp. 331-33.

[18] 18.Cocanour CS, Miller-Crotchett P, Reed RL II, Johnson PC, Fischer RP. 1992; Mucormycosis in trauma patients. J Trauma ;32:12-5

[19] 19. Pablo C. Okhuysen, John H. Rex, Mario Kapusta, and Caroline Fife. 1994; Successful Treatment of Extensive Posttraumatic Soft-Tissue and Renal Infections Due toApophysomyces elegans; Clin Infect Dis. 19 (2):329-331.

[20] 20. Winkler G. Weinberg, Barbara H. Wade, George Cierny, III, David Stacy and Michael G. Rinaldi; Nov 1993. Invasive Infection Due to Apophysomyces elegans in Immunocompetent Hosts Clinical Infectious Diseases, Vol. 17, No. 5 ; pp. 881-884.

[21] 21. Julie A. Ribes, Carolyn L, Vanover-Sams, and Doris J. Baker. April 2000; Zygomycetes in Human Disease. Clin. Microbiol. Rev. ;13:236-30

[22] Wilfred P. dela Cruz, Tatjana P. Calvano, Matthew E. Griffith, Christopher E, White, Seung H. Kim, Deanna A. Sutton, Elizabeth H. Thompson, Jianmin Fu, Brian L. Wickes,Josep Guarro,and Duane R. Hospenthal. August 2012; Invasive Apophysomyces variabilis Infection in a Burn Patient. J Clin Microbiol. 50(8): 2814-17.

[23] Boelaert JR, de Locht M, Van Cutsem J, Kerrels V, Cantinieaux B, Verdonck A, Van Landuyt HW, Schneider YJ. 1993 May; Mucormycosis during deferoxamine therapy is a siderophore-mediated infection: in vitro and in vivo animal studies. Journal of Clinical Investigation.;91(5):1979-1986.

[24] Maureen M. Roden1, Theoklis E. Zaoutis, Wendy L. Buchanan Tena A. Knudsen, Tatyana A. Sarkisova, Robert L. Schaufele, Michael Sein, Tin Sein, Christine C. Chiou, Jaclyn H. Chu, Dimitrios P. Kontoyiannis, and Thomas J. Walsh; Sep 2005 Epidemiology and Outcome of Zygomycosis: A Review of 929 Reported Cases Clinical Infectious Diseases, Vol. 41, No. 5, pp. 634-653

[25] Josep Guarro, Jagdish Chander, Eduardo Alvarez, Alberto M. Stchigel, Kaushik Robin, Usha Dalal, Hena Rani, Rajpal S. Punia, and José F. Cano. Jan 2011 Apophysomyces variabilis Infections in Humans. Emerg Infect Dis. ; 17(1): 134-135

[26] Kizee A. Etienne, John Gillece, Remy Hilsabeck, Jim M. Schupp, Rebecca Colman. Shawn R. Lockhart, Lalitha Gade, Elizabeth H. Thompson, Deanna A. Sutton, Robyn Neblett-Fanfair, Benjamin J. Park, George Turabelidze, Paul Keim2,Mary E. Brandt, Eszter Deak, David M. Engelthaler. (2012) Whole Genome Sequence Typing to Investigate the Apophysomyces Outbreak following a Tornado in Joplin, Missouri, 2011. PLoS ONE 7(11):e49989

[27] Chakrabarti A, Shivaprakash MR, Curfs-Breuker I, Baghela A, Klaassen CH, J.F.Meis (2010) Apophysomyces elegans: epidemiology, amplified fragment length polymorphism typing, and in vitro antifungal susceptibility pattern. J Clin Microbiol 48 : 4580-4585

[28] M.Richardson(2009) The ecology of the Zygomycetes and its impact on environmental exposure.Clin Microbiol Infect 15:2-9. )

[29] Snell BJ, Tavakoli K.(2007); Necrotizing fasciitis caused by Apophysomyces elegans complicating soft-tissue and pelvic injuries in a tsunami survivor from Thailand. Plast Reconstr Surg; 119: 448-44

[30] Hibbett DS, Manfred Binder,et.al 2007; A higher-level phylogenetic classification of the Fungi. Mycol Res; 111(Pt 5): 509-5

[31] Kimberly P. Liang, Imad M. Tleyjeh, Walter R. Wilson, Glenn D. Roberts, and Zelalem Temesgen. March 2006; Rhino-Orbito cerebral Mucormycosis Caused by Apophysomyces elegans Clin Microbiol. 44(3): 892-898 